\title{
Monitoring Student Engagement in First Year Engineering
}

\author{
Geraldine Van Gyn and Peter Wild \\ University of Victoria \\ gvangyn@uvic.ca and pwild@uvic.ca
}

\begin{abstract}
In a 2006 study to assess student engagement in the first year, engineering students were the least likely to express positive views about that experience and reported low levels of academic engagement. Initiatives to address this situation in engineering were in progress, including the development of two first year courses integrated engineering design with required writing courses. To monitor engagement and satisfaction, and assess the impact of the course interventions, the same research methodology as the 2006 study was used in 2010, 2011, and 2012 following the implementation of these courses. Participants in focus groups discussed questions related to engagement and identified factors that had led to their satisfaction or dissatisfaction. Themes identified for the three different time periods were compared to each other and to those that emerged in the original 2006 study. Significant among the themes was the experience in the design/communications courses. Themes of dissatisfaction and alienation were highly consistent with the 2006 study but became moderated. This process reinforced the need for authentic engineering course experiences in the first year and is consistent with previous research.
\end{abstract}

Key Words: student engagement, authentic experience, engineering design, student-faculty contact, workload.

\section{INTRODUCTION}

There has been a long-standing concern with the retention of students in North American engineering programs [1] particularly in the initial years of the traditional four-year undergraduate program. It is not uncommon that $40 \%$ of first year engineering students do not advance to the next year. This phenomenon is highly inefficient from a resource perspective and, most likely, discourages students from choosing engineering in the first place. It has been reported, however, that both persistence and engagement in engineering programs, beyond first year, is similar to that of students in other majors [2]. This suggests that persistence is a function of degree of student engagement and, therefore, must be not only a program priority but also an institutional priority.
A logical extension of these findings is that initiatives to increase student engagement in the first year of a program are critical to improving the retention rates as well as improving the educational value of first year.

The concept of student engagement is multidimensional and characterized by the time students devote to activities that are of benefit to their learning. As well, it is comprised of the ways in which students approach these tasks with strong student engagement reflected in the use of independent and self regulated learning strategies [3]. Student engagement, at the course level, is characterized by "the student's concentration of attentional, cognitive and affective resources" [3, p. 339] towards the educational tasks to be completed. As such, it is similar to the concept of deep learning [4] described as an intention to learn and understand, as opposed to surface learning, which is typified by an intention to remember for examinations. Students' disposition to engage in deep or surface learning is a critical element; however, both student engagement and deep learning can be encouraged by pedagogical means, in that the learning conditions are meaningful to students and motivate them to apply quality effort to their courses.

This current study came about through the interest of an engineering faculty member in the results of 2006 panuniversity research on the first year experience. The 2006 qualitative study [5] identified first year engineering students as the least engaged and the most dissatisfied with the first year experience of all first year disciplinary groups. A major theme derived from the student narratives was a perceived lack of relevance or connection of first year courses to the study of engineering. The discussion of these results coincided with an initiative to introduce an two integrated engineering design and communications courses in the first year of the program (Engr. 110 and $120^{1}$ ) with the intention of increasing the relevance of the university English requirements for engineers and to provide an authentic engineering experience early in the program. In September 2009, Engr. 110 was launched and in January 2011, Engr. 120

\footnotetext{
1 See Paper 03 in these proceedings entitled "Effects of first year integrated writing and design curriculum on writing achievement: Results of a two year assessment study." for a description of the courses.
}

CEA13; Paper 144

Montreal, QC; June 17-20, 2013

\section{-1 of 6-}


was added to the curriculum. The primary purpose of the current study was to assess the effectiveness of these two integrated courses in increasing student engagement and student satisfaction with the first year engineering experience. As the initial 2006 research was qualitative in nature, the current research was conducted with the same paradigmatic approach.

\section{METHODOLOGY}

\subsection{Research Design}

To achieve the objectives related to the efficacy of the curriculum changes, we used an educational design experiment [6] as it constitutes an important methodological tool for maximizing the effectiveness of curriculum. After each implementation of the course, adjustments are made based on various sources of evidence. The specific curriculum design changes are not the focus of this study, but the data from this study informed the changes. A baseline of themes on engineering student engagement and satisfaction regarding the first year experience was established in 2006, and the protocols from that study were followed in the subsequent three data collection periods. Data collected in 2010 (CDC1) followed the introduction of ENGR 110, where as the subsequent two data collection periods (CDC2 and CDC3) followed student participation in both ENGR 110 and 120 (Table 1). The Human Research Ethics Board of the University of Victoria approved this research.

\subsection{Participants}

Ninety-two engineering student participated in the research. Forty-three students (29 in the first and 14 in the second year) were involved in the 2006 baseline study and 48 first year engineering students participated in the 2010 12 portion of the study, with 18 participants in 2010, 14 in 2011, and 16 in 2012. We reduced the number of focus groups in the 2010-12 period as we did not include second year students and a minimum of two focus groups was sufficient for the methodology

\subsection{Procedures}

A focus group method was used to explore students' views of, and experiences in, the first year of their engineering program. Each group was made up of five to seven students (Table 1).
Table 1. Schedule for the research data collection

\begin{tabular}{|c|c|c|c|}
\hline $\begin{array}{l}\text { Date } \\
\text { Collection } \\
\text { Periods }\end{array}$ & $\begin{array}{l}\text { Academic } \\
\text { Term } 1\end{array}$ & $\begin{array}{l}\text { Academic } \\
\text { Term } 2\end{array}$ & $\begin{array}{l}\text { Focus } \\
\text { Group Identity } \\
\text { and Number of } \\
\text { Participants }\end{array}$ \\
\hline $\begin{array}{l}2005-06 \\
\text { Baseline } \\
\text { Data } \\
\text { Collection } \\
\text { BCD }\end{array}$ & $\begin{array}{l}\text { Traditional } \\
\text { required } \\
\text { first year } \\
\text { courses }\end{array}$ & $\begin{array}{l}\text { Traditional } \\
\text { required } \\
\text { first year } \\
\text { courses }\end{array}$ & $\begin{array}{l}\text { A (5) } \\
\text { B (6) } \\
\text { C (7) } \\
\text { D (7) } \\
\text { E (7) } \\
\text { F (6) } \\
\text { G (5) }\end{array}$ \\
\hline $\begin{array}{l}2009-10 \\
\text { Comparison } \\
1 \\
\text { CDCI }\end{array}$ & $\begin{array}{l}\text { Introduction } \\
\text { of ENGR } \\
110 \text { as a } \\
\text { required } \\
\text { course }\end{array}$ & $\begin{array}{l}\text { Traditional } \\
\text { required } \\
\text { first year } \\
\text { courses }\end{array}$ & $\begin{array}{l}\text { A (6) } \\
\text { B (6) } \\
\text { C (6) }\end{array}$ \\
\hline $\begin{array}{l}2010-11 \\
\text { Comparison } \\
2 \\
\text { CDC2 }\end{array}$ & ENGR 110 & $\begin{array}{l}\text { Introduction } \\
\text { of ENGR } \\
120 \text { as a } \\
\text { required } \\
\text { course }\end{array}$ & $\begin{array}{l}\text { A (7) } \\
\text { B (7) }\end{array}$ \\
\hline $\begin{array}{l}2011-12 \\
\text { Comparison } \\
3 \\
\text { CDC3 }\end{array}$ & ENGR 110 & ENGR 120 & $\begin{array}{l}\text { A (5) } \\
B(5) \\
C(6)\end{array}$ \\
\hline
\end{tabular}

Engineering students were recruited in one of their courses and those interested provided an email contact to the researcher. The researcher followed up with a detailed explanation of the study. A consent form was also sent to them along with a timetable for focus groups. If they signed up for a group, they came with the consent form that was reviewed and signed before any discussion was initiated. Each focus group was 1.5 hours in length.

A standard set of questions and one card sorting exercise was used to elicit and facilitate discussion in the focus group, but critical to the success of the focus group was the discussion among participants as they challenged each others' views and expanded on their comments. Focus group questions were designed to explore the various facets of student engagement as identified by Kuh [7] including active learning, supportive learning conditions and student-faculty and student-student contact. The card sorting exercise was done in pairs as students ranked, in terms of frequency, the type of cognitive activities they had experienced in their first year courses (memorizing, comparing, analyzing, synthesizing, problem solving, making critical judgments) and then explained their rankings to the group.

In $\mathrm{CDC} 1,2$, and 3, the students were not asked specifically about the ENGR 110 or 120 courses. The researcher only asked the standard questions related to student engagement, as in BDC. Once students introduced the courses in question into the discussion, 
then the researcher probed more deeply on the subject of these two courses.

\subsection{Data Analysis}

Each focus group discussion was transcribed and the data were entered into NVivo, a standardized software tool which, in this case, managed the data for a thematic analysis. The initial step is to read through the transcripts repeatedly to become familiar with the data and then to create broad codes or categories to reduce the amount of data handled at one time. Following this step is the more specific coding of the data, and identification of semantic and latent themes that emerge from this encoding of the data. A theme is a concept, or a pattern, or category of responses that occurs with regularity. If a theme is explicit, it is identified as semantic. A latent theme is one that requires the researcher's interpretation of what is expressed by the participants. [8] Following the analysis, a participant from each of the focus groups was asked to read the themes and descriptions that the researcher identified to corroborate or provide clarifying feedback.

The themes were compared to the baseline and to the period(s) that preceded it. The comparisons were conducted to assess replication of themes, modifications of themes and strength of themes.

\section{RESULTS and DISCUSSION}

\subsection{Baseline (BDC)}

From the baseline data, eleven themes were identified. We made an effort not to over-interpret the voices of the students so the themes were mainly semantic. Only six themes will be discussed, as they are most pertinent to student engagement issues. Some student quotations are included as exemplars of each of the themes.

Theme 1 Minimal educational engagement in class. This theme emerged mainly from discussions of course activities. Engagement, in the context of this research, refers to the opportunities that student have to ask questions, take part in discussions, work with professors and/or other students on the concepts that are being learned in the course. In general, educational engagement reflects the degree of intellectual activity that is occurring, including critical thinking and other higher-level cognitive activities.

The dominant student perspective on educational engagement was that most of their learning took place outside of class. Students reported that the majority of the time in class was given over to delivery of content, and not necessarily to ensuring that students understood this content. Students were able to identify conditions under which some engagement occurred (e.g., opportunities for questions, meaningful assignments that are reviewed in class, good examples, in-class activities that are meaningful and challenging), but for the most part indicated that they were passive in class. There was a significant expression of frustration about the amount of time spent outside the course struggling with understanding core concepts.

I find a lot of them do not have a lot of time anyways [to answer questions/engage in discussions]. They are trying to rush you through. They do not give you a lot of time. You might need a little bit of time to spend on that subject until you understand it. They just give you the quick gist of it and then move on.

Theme 2. Expressed need for engagement with professors. Learning is a challenging activity and, for many students, feeling that they have the support of the professor in meeting this challenge is reassuring. Engineering participants clearly indicated that professors who made any effort to help them to learn, to acknowledge their work, to provide opportunities to work with the concepts, or to share with them about their own learning experiences, either as a student or as a professional, were highly appreciated.

(in discussion of an exemplary professor) The best thing and it is the first thing I have ever seen out of any professor is he turns around and says, "Do you understand?" You will see half the class raise their hands. He will go over it again. That is the first and rarest opportunity I have ever seen. Not only does he want you to learn but he has demonstrated that he actually cares. Even if he has 200 people sitting in front of him. We all feel like one small collective group. That helps.

Theme 3. Look to your left and now to your right. Of the three of you, only one will make it through this year. Many of the first year students who participated in the focus groups were in "survival mode". Although only one student stated that he/she was failing, many students reported that many of their classmates had dropped out or switched to another program, after first term.

Of particular importance to educational success is a positive perception of control over one's learning and a positive perspective on the experience. Students who perceive that they have academic control tend to work harder, are less anxious and more motivated, are able to use self-monitoring strategies to sustain their academic work, and generally perform better academically [9]. For many in the focus groups, these characteristics were not evident, It would be speculation to suggest that they did not have a high level of perceived control as we did not measure this; none-the-less students appeared anxious and, and in some cases, resigned to the high probability for failure that they perceived as inherent in the engineering education culture. There was a general level of anger and hostility about their learning experiences and 
they tended to attribute their difficulties to instructors as opposed to themselves.

They inflict these courses or these professors on us to demonstrate that it is hard work and then those people who do not want to work hard get out.

We are not getting the help we need in order to complete the assignments that we are tested on. I guess they figure that if we can't do it then we shouldn't be in the program

The reason why they are so rough on the Engineering students in the first semester is to weed out the people who really do not want to be there.

Theme 4. Lots of content and little time. Substantial course workloads and lack of time to complete the work was a clear theme in all focus groups. Students also made reference to a lack of time in class to ask questions or to have discussions, which could account for the perceived lack of engagement with professors, other students, and with the course material. Their descriptions of their work in class, and how they attempted to make sense of the course material out of class, suggests a lack of broader conceptual framework in which to organize their learning. Without such a framework, students do not identify connections or find meaning in the content and this tends to result in learning for reproduction for examinations (see Theme 5. Surface Learners). Students were also quite negative about the instructors who assigned a workload that was perceived as excessive. Research [10] indicates that instructors are able to create conditions that encourage students to do high volumes of quality work without being criticized for demanding too much work. These conditions include organized curricula with clear goals, and obvious relationships among conceptual components, instructional activities that focus on course concepts to promote understanding, relevant discussions, projects and group work, assessment activities that focus on understanding rather than memorization, and supportive instructor-student relationships.

All I have learned since I got here is how to deal with time management and how to get the assignments done.

There is just no way you can do that much homework and live. These [professors] have no idea and they are terrible teachers -I don't think they could do [what was required].

Theme 5. Surface learners. Students tend to take an approach to learning that they believe is appropriate for the educational conditions they experience [7]. As previously described, surface learning, or learning to reproduce for examinations, occurs when students perceive that there is excessive content and when they are given little time to work with the content to understand it Surface learning has also been correlated with lack of choice in subjects and/or methods of study and with high stakes assessment. The focus in surface learning is mainly memorization as opposed to analysis for understanding or some other intellectual activity that will deepen the students' understanding of the material. Outcomes from surface learning include short-term retention and the generation of few linkages among concepts, both of which result in poor transfer to other areas of study or to an application. [4]

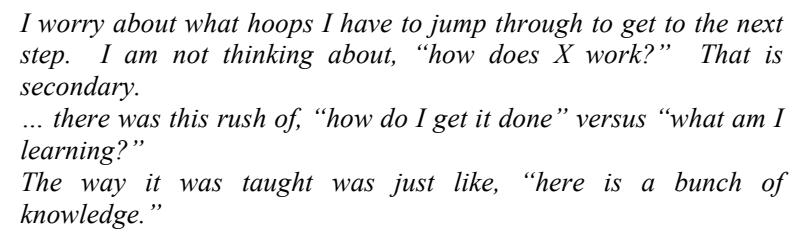

I worry about what hoops I have to jump through to get to the next step. I am not thinking about, "how does X work?" That is secondary.

... there was this rush of, "how do I get it done" versus "what am I learning?"

The way it was taught was just like, "here is a bunch of knowledge."

Theme 6. Expectations for opportunities to apply knowledge. Many students expressed disappointment at the lack of knowledge application opportunities. Although they identified some application activities, it was generally in the context of applying a formula or a particular rule. Some of the participants, mainly second year students, spoke enthusiastically about their experiences in design projects, all of which were extracurricular. Their enthusiasm for both the activity and the unexpected benefits was obvious. It appeared that the experiences in the extracurricular design activities were meaningful to the students and they were learning at a deep level.

Yeah, I joined that project too. I have to say it was kind of cool. It was fun to find equations that would relate to that, like radiators. You hope it will not blow up.

\subsection{Introduction of ENGR 110 (CDC1)}

Many of the baseline themes were also evident in the $\mathrm{CDC} 1$ focus group discussions of their first year experience. Theme 1 (Minimal educational engagement in courses) was expressed strongly in reference to many of their required courses. A notable exception was ENGR 110. Students were not wholly positive about the course but did identify the laboratory design experience as challenging, relevant, and providing some links to other courses.

\section{Figuring out how to get the bridge to work was awesome. We really worked hard in our group and everyone contributed. The final presentation was stressful but I think it was the highlight of the year.}

This course was also implicated in the expression of Theme 5 (Expectations for opportunities to apply knowledge). They identified this course as different from all others and expressed the excitement and interest in the design process that the baseline students displayed in their involvement in extracurricular project activities. 
Although Themes 3 (Look to your left.), 4 (Lots of content little time) and 5 (Surface learners) were clearly identifiable, the level of hostility and concern with failure appeared lower and there was a more positive tone to the discussions. Students returned repeatedly, in their comments, to the ENGR 110 experience and when questioned by the researcher about the course, were unanimous about its positive effect.

It was so different because we really got to do something. Even the English part was good because we were reading articles on engineering design and reporting our work.

Yeah it was a lot of work too but it was a lot more fun than X. You don't mind putting in the hours when you are working on a real project.

Theme 2 (Expressed need for engagement with professors and course material) was apparent in the discussion of these focus group participants. Students tended to use the example of ENGR 110 in contrast with other course experiences in which students were not engaged.

Yeah so why can't other courses be like (Engr). 110? Our X course was so bad that I just quit going. I just used the time to study from the text and checked with my friend to find out what was going on. Then I had to get a tutor. At least in (ENGR) 110 you got to talk to the lab instructors and the TA's and they really tried to help us to figure out the stuff for the reports.

Through the discussion of ENGR 110, the first new theme (New theme 1. We were learning but they (instructors) were learning too!) emerged and identified some problems to be addressed in the course. Students commented that the communications between course personnel was poor and they appeared disorganized. This theme was strongly expressed in all three groups and very specific examples were given relating to instructions, feedback, and courses processes. None-the-less, students seemed to appreciate that this was the first implementation of the course and, given the number of students and multiple facets of the course, preparation would improve.

I get that this was the first time for this course. The profs really tried hard to make it all fit together but I think they need to be better prepared.

It was like a big jigsaw puzzle and it was hard to keep track of what was happening but at the end, it worked out. Now that the instructors have done it once, next year should be a lot better.

A second new theme (I feel like an engineer) was more positive and identified ENGR 110 as a critical variable in feeling part of the engineering community.

I think I have a better idea about what engineers do and even doing that the parts of the bridge project made me feel like ... sure I can be an engineer.

We really worked as a team. We had some problems but most we got to work out ourselves. They said at the beginning of the course that working on a team was super important in engineering so I get why we had to do that. At the end, it was worth it... Our bridge was the best, I think.

From this feedback and that from other sources, changes were made to ENGR110 and the first implementation experience influenced the design of ENGR 120, as the curriculum for that course was being prepared.

\subsection{Second implementation of ENGR 110 and introduction of ENGR 120 (CDC2)}

Students participating in the 2011 focus groups had taken both ENGR 110 and 120. Themes from the CDC2 cohort were very similar to those of CDC1. The topic of ENGR 110 and 120 came up early in the discussions in response to the question "What were the academic highlights of your first year?"

Definitely ENGR 110 and 120. These two courses helped me to stay sane! These courses were so much more fun and interesting than the others. We got to work like engineers-well sort of (group laughter).

Themes related to excessive content and lack of relevance were still evident, but, as in the previous year, the negativity was markedly diminished. Students referred less to failure in the program and more to specific examples of student-faculty engagement and relevant challenge. Theme 1 (Expressed need for engagement with professors and course material) was reinforced as students spoke of the positive level of engagement in ENGR 110 and 120.

\footnotetext{
Doing the projects (in ENGR 110 and 120) made me think of all sorts of connections that never occurred to me before about engineering.

Working with the lab people was great. The grad students were so helpful and made me feel that I was on the right track in engineering.

It wasn't easy-but working hard in that course (ENGR 110) felt good 'cause we were working towards a goal.

Sometimes, I thought 'what am I doing in engineering?' but those courses helped me to focus on the bigger picture. Courses $X$ and $Y$ really didn't help me with that.
}

Particularly evident in the focus groups of this cohort was the level of collegiality among students. There was friendly banter and reminiscence about their projects. This new theme 3 (We are a team) was very positive and given the discussions ENGR 110 and 120 appeared to be related to their experiences in these courses.

\footnotetext{
Our group was amazing and we still are connected. It really helps to have a group of people that you know that can work and are in other courses. You know they aren't slackers.

This year was really crazy-making but the guys in my project group -we really bonded (group laughter)—ok, ok, I mean the team thing worked and it was fun. So we are friends and we help each otherand party!
}

CEA13; Paper 144

Montreal, QC; June 17-20, 2013

\section{-5 of 6-}




\subsection{Third implementation of ENGR 110 and second implementation of ENGR 120 (CDC3)}

No unique new themes emerged from $\mathrm{CDC} 3$, but the three new themes identified in $\mathrm{CDC} 1$ and 2 were evident. One modification in the new themes was the decrease in the concerns about the organization of the courses (New Theme 1. We were learning but they (instructors) were learning too!) reflecting the fact that instructors were better prepared to manage the complexity of the meld of the plenary sessions, the laboratories and the communications sessions. New theme 1 appeared to be evolving into We were learning and the instructors were working as a team.

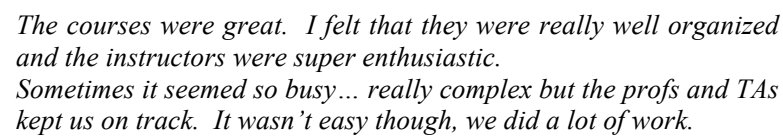

Negative themes were still identifiable and these related mainly to lack of relevance in courses other than ENGR 110 and 120, excessive content, fear of failure, and surface learning under these conditions

\subsection{GENERAL DISCUSSION AND CONCLUSIONS}

Over the period 2010-2012, student academic engagement, as evidenced by the theme comparisons and emergence of new themes, appeared to increase. The major factor in this change, as identified in their discussions, was ENGR 110 and 120 both of which required active involvement in authentic design activities. Efforts were made in the design of these courses to incorporate the features identified by numerous studies as necessary to engage students in their academic work. The impact of these features (e.g., active involvement through authentic projects, sufficient and informative feedback, student-instructor interaction, meaningful assessment which aligned with course activities) appeared to produce willingness to work with effort, in this course. It also appeared to mitigate the anxiety and fear of failure evident in the 2006 cohort, consistent with other studies [9].

The findings were not unexpected, given the research on student engagement. As well, we cannot attribute these changes solely to the courses, as the context in which this research was done was not static. None-the-less, monitoring student engagement as curriculum changes provides evidence for influences of the course design on student learning. As instructors used student feedback to make modifications, and as they, themselves, became more comfortable with the course design, student perspectives on the course become more positive and they reported deeper engagement. This outcome speaks to the need for excellent initial course design resources as well as time to allow complex courses, such as ENGR110 and 120 , intended to engage students in relevant and authentic experiences, to mature and enable their full impact.

\section{Acknowledgements}

This research was supported by a grant from the UVic Learning and Teaching Centre. We extend our thanks to Sean McConkey, Yvonne Cody, Michael McGuire, and Suzan Last who helped immeasurably with the research.

\section{References}

[1] Christina Vogt, "Faculty as a critical juncture in student retention and performance in engineering programs." Journal of Engineering Education, vol. 97, no. 1, pp. 27-36, 2008.

[2] Mathew Ohland, Sheri Shepard, Gary Lichtenstein, Ogar Eris, Debbie Chachra, and Richard Layton. "Persistence, engagement, and migration in engineering programs." Journal of Engineering Education, vol. 97 no. 3, pp. 259278. 2008.

[3] Helen Chen, Lisa Lattuca, Eric Hamilton. "Conceptualizing engagement: Contributions of faculty to student engagement in engineering." Journal of Engineering Education, vol.97, no. 3, pp. 335-359, 2008.

[4] Ference Marton and Roger Säljö. "On qualitative differences in learning - I: Outcome and process." British Journal of Educational Psychology, vol. 46, pp. 4-11, 1976.

[5] Geraldine Van Gyn. "Student engagement: a pan-university study." An unpublished report produced for the Vice President Academic, University of Victoria, 2006.

[6] Paul Cob, Jere Confrey, Andrea diSessa, Richard Lehrer and Leona Schauble. "Design experiments in educational research." Educational Researcher, vol. 32, no.1, pp.9-13, 2003.

[7] George Kuh. "Student engagement in the first year of college." In Challenging and Supporting the First-year Student: A Handbook for Improving the First year of College. L. Upcraft, J. Gardner, and B.Barefoot (Eds.), San Francisco: Jossey-Bass, 2007.

[8] Ray Perry, Steven Hladkyj, Reinhard Pekrun, and Sarah Pelletier. "Academic control and action control in the achievement of college students: A longitudinal field study." Journal of Educational Psychology, vol. 93, pp. 776-789, 2001.

[9] David Kember. "Interpreting student workload and the factors which shape students' perceptions of their workload." Studies in Higher Education, vol. 29, no. 2, pp. 165-184, 2004.

CEA13; Paper 144

Montreal, QC; June 17-20, 2013 
Proc. 2013 Canadian Engineering Education Association (CEEA13) Conf.

CEA13; Paper 144

Montreal, QC; June 17-20, 2013

-7 of 6- 